\title{
Structural and hygroscopic changes of soot during heterogeneous reaction with $\mathrm{O}_{3}$
}

\author{
Yongchun Liu, Chang Liu, Jinzhu Ma, Qingxin Ma and Hong He* \\ Received 30th April 2010, Accepted 19th May 2010 \\ DOI: $10.1039 /$ c0cp00402b
}

Soot aerosols are ubiquitous in the atmosphere and play an important role in global and regional radiative balance and climate. Their environmental impact, however, greatly depends on their structure, composition, particle size, and morphology. In this study, the structural changes of a model soot (Printex U) during a heterogeneous reaction with $80 \mathrm{ppm} \mathrm{O}_{3}$ at $298 \mathrm{~K}$ were investigated using in situ Raman spectroscopy, in situ diffuse reflectance infrared Fourier transform spectroscopy (DRIFTS), and transmission electron microscopy (TEM). Hygroscopic changes due to heterogeneous reaction with $\mathrm{O}_{3}$ were also studied by water sorption analyzer. The consumption of amorphous carbon ( $D 3$ band) and disordered graphitic lattice ( $D 4$ band) of soot by ozonization was confirmed by the decrease in the full widths at half maximum and their relative integrated intensities (percentages of integrated areas). Oxygen containing surface species including ketone, lactone, and anhydride were also observed in Raman and IR spectra of ozonized soot. The ozonized soot showed more compacted aggregates with a smaller average diameter of primary particles $(29.9 \pm 7.7 \mathrm{~nm})$ and a larger fractal dimension $(1.81 \pm 0.08)$ when compared with fresh soot $(36.9 \pm 9.4 \mathrm{~nm}$, and $1.61 \pm 0.10)$. The ozonization reaction leads to an enhancement of hygroscopicity of soot due to the decrease in particle diameter and the formation of oxygen containing surface species.

\section{Introduction}

Soot aerosols produced from fossil-fuel combustion and biomass burning are chain-like agglomerates of primary particles, which consist of perturbed graphitic layers oriented concentrically in an onion-like fashion. ${ }^{1}$ They are ubiquitous in the atmosphere and comprise $\sim 10-50 \%$ of the total tropospheric particulate matter. ${ }^{2-5}$ Soot aerosols play an important role in global and regional radiative balance and climate, both directly by absorbing solar and terrestrial radiation and indirectly by serving as cloud condensation nuclei $(\mathrm{CCN}) .{ }^{4,6}$ The contribution of soot to global warming is perhaps only second to that of $\mathrm{CO}_{2} \cdot{ }^{3}$ It may also be responsible for the increase in summer droughts and floods in northeast and southeast China observed over the last 20 years. ${ }^{4}$ However, the impacts of soot on climate change are associated with a high degree of uncertainty ${ }^{7}$ because the absorptive properties of soot can change by a factor of two or more depending on its source and atmospheric processing. ${ }^{4}$ This high degree of uncertainty highlights the importance of soot's structure, composition, and morphology on its environmental impacts. In particular, soot particles emitted into the atmosphere are subjected to several aging processes, including adsorption or condensation of gaseous species, coagulation with other preexisting aerosols, and oxidation. ${ }^{5}$ These processes significantly alter the structure, composition and morphology of soot. ${ }^{5,8,9}$

State Key Laboratory of Environmental Chemistry and Ecotoxicology, Research Center for Eco-Environmental Sciences, Chinese Academy of Sciences, Beijing, 100085, China.E-mail: honghe@rcees.ac.cn;

Fax: 86-10-6292-3563; Tel: 86-10-6284-9123
Over the past several decades, investigations have been conducted on the heterogeneous reaction between soot and $\mathrm{O}_{3}{ }^{10-17}$ due to its potential contribution to $\mathrm{O}_{3}$ depletion in the upper troposphere (UT) and low stratosphere (LS) ${ }^{10}$ and also the increase in hygroscopicity of soot itself. ${ }^{18}$ Several studies have measured the uptake coefficient $(\gamma)$ of $\mathrm{O}_{3}$ on different types of soot including model soot samples produced in the laboratory by combusting n-hexane, ${ }^{10,12}$ toluene,,${ }^{11,13}$ kerosene,${ }^{11}$ and mixtures of hydrocarbons, ${ }^{13}$ and by spark discharge generator with graphite electrodes; ${ }^{16}$ commercial soots such as Degussa FW1 and FW2 $;^{17}$ and diesel soot. ${ }^{11}$ The reported values of $\gamma$ are highly variable from $10^{-3}$ to $10^{-8}$ depending on the soot surface area accessible to $\mathrm{O}_{3}$, soot type and soot deactivation process, and $\mathrm{O}_{3}$ concentrations used. ${ }^{13}$ Such variability has contributed to the uncertainty of whether or not soot aerosols contribute to $\mathrm{O}_{3}$ depletion. ${ }^{14,19,20}$

In addition, previous research has proposed that the reaction mechanism proceeds via a Langmuir-Hinshelwood mechanism based on kinetic studies, ${ }^{12,15,16,21}$ with $\mathrm{CO}_{2}$, $\mathrm{H}_{2} \mathrm{O},{ }^{22}$ and $\mathrm{CO}^{23}$ observed as gaseous products. Possible surface products, including ketone, lactone, and anhydride, were also detected by using infrared spectroscopy, ${ }^{11}$ chromatography, and nuclear magnetic resonance spectroscopy (NMR). ${ }^{24}$ Uncertainties still exist, however, concerning the rate and mechanism at which these particles oxidize. ${ }^{12}$ In particular, little is known regarding how soot participates and how the structure of soot changes in this reaction. Considering the potential role of soot structure regarding its environmental impact, investigating the structural changes of soot in the atmospheric aging processes is very important.

In this study, the structural changes of a model soot during reaction with $\mathrm{O}_{3}$ were observed using Raman and infrared 
spectroscopy (IR). The morphological changes were investigated by transmission electron microscopy (TEM). The hygroscopic changes due to heterogeneous reaction with $\mathrm{O}_{3}$ were also studied using water sorption analyzer. The results will increase understanding of the aging process of soot in the atmosphere and may also help assess environmental effects dependent on soot structure.

\section{Experimental section}

\section{Materials and characterization}

Printex U powder from Degussa (CAS No.: 1333-86-4) was used as a model soot aerosol as it is considered a good representation of diesel soot. ${ }^{25,26}$ The specific surface area was $97.24 \mathrm{~m}^{2} \mathrm{~g}^{-1}$, measured using nitrogen Brunauer-Emmett-Teller (BET) physisorption (Quantachrome Autosorb-1-C).

\section{Experimental methods}

In situ Raman spectra for the reaction of soot with $\mathrm{O}_{3}$ were recorded on a UV resonance Raman spectrometer (UVR DLPC-DL-03), which consisted of three optional exciting lasers $(244 \mathrm{~nm}, 325 \mathrm{~nm}$, and $532 \mathrm{~nm})$, a three-stage grating spectrograph, and a CCD detector cooled by liquid nitrogen. The instrument was calibrated against the Stokes Raman signal of Teflon at $1378 \mathrm{~cm}^{-1}$. A continuous diode pumped solid state (DPSS) laser beam $(532 \mathrm{~nm})$ was used as the exciting radiation, with the adjustable source power ranging from 0 to $200 \mathrm{~mW}$. A source power with $40 \mathrm{~mW}$ was used and no sample modification was observed when the sample was irradiated under the experimental conditions. The diameter of the laser spot on the sample surface was focused at $25 \mu \mathrm{m}$. The spectra resolution was $2.0 \mathrm{~cm}^{-1}$.

Soot powder was placed into a Teflon sample holder and

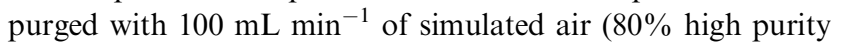
$\mathrm{N}_{2}$ and $20 \%$ high purity $\mathrm{O}_{2}$ ) for $12 \mathrm{~h}$ at $298 \mathrm{~K}$. Then, $80 \mathrm{ppm}$ of

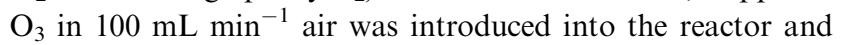
in situ Raman spectra were recorded. The $\mathrm{O}_{3}$ was generated by irradiation mixture flow of high purity $\mathrm{O}_{2}$ and $\mathrm{N}_{2}$ using a mercury lamp with wavelength of $184 \mathrm{~nm}$. The concentration of $\mathrm{O}_{3}$ was measured by an ozone monitor (2B Technology). The temperature was held at $298 \mathrm{~K}$ during the reaction. To avoid the influence of visible light on the heterogeneous reaction, the sample was only exposed to the exciting laser for spectra collection. The exposure time for each scan was $50 \mathrm{~s}$.

The in situ infrared spectra were recorded by a diffuse reflectance infrared Fourier transform spectroscopy (DRIFTS, Nicolet 670) described previously. ${ }^{27}$ Because of the soot sample's strong absorption of the IR beam, the sample was diluted with $\mathrm{KBr}$ to $1: 200$. The reaction conditions in the DRIFTS experiment were the same as that in the Raman experiment. The resolution of the reported IR spectra was $4.0 \mathrm{~cm}^{-1}$ for 100 scans and the reference spectrum was recorded using the unreacted sample.

A transmission electron microscope (H-7500, Hitachi) was used to investigate the morphologies of soots before and after heterogeneous reaction with $\mathrm{O}_{3}$. Soot samples were ultrasonically dispersed in ultrapure water (18 M $\Omega$ ) and a droplet of suspending liquid was deposited onto a $\mathrm{Cu}$ microgrid. An acceleration voltage of $80 \mathrm{kV}$ was used for measurements. The diameter of primary particles and project area of aggregates for fractal dimension analysis were analyzed by ImageJ 1.41 software.

Water uptake of fresh soot and $\mathrm{O}_{3}$ aged soot samples were performed on a Quantachrome Autosorb-1-C instrument equipped with a vapor generator. ${ }^{28}$ Adsorption capacity of water was measured based on the conventional volumetric method. The soot sample exposed to $80 \mathrm{ppm} \mathrm{O}_{3}$ at $298 \mathrm{~K}$ for $19 \mathrm{~h}$ represented $\mathrm{O}_{3}$ aged soot. Prior to the water uptake experiments, the samples were outgassed at $3.0 \times 10^{-3}$ Torr and at $353 \mathrm{~K}$ for $24 \mathrm{~h}$ to remove the adsorbed water. The temperature of the sample during the water uptake experiment was held at $278.15 \pm 0.1 \mathrm{~K}$ by a super thermostat and a cryofluid pump (DFY 5/80, Henan Yuhua laboratory instrument factory).

\section{Results and discussion}

\section{Raman spectra of soot during heterogeneous reaction with $\mathrm{O}_{3}$}

Fig. 1A shows the in situ first-order Raman spectra in the range of $800-2000 \mathrm{~cm}^{-1}$ for the heterogeneous reaction of soot (Printex U) with 80 ppm $\mathrm{O}_{3}$ at $298 \mathrm{~K}$. The control Raman spectra in simulated air (without $\mathrm{O}_{3}$ ) are shown in Fig. 1B. Typical bands of soot around $1580 \mathrm{~cm}^{-1}$ ( $G$ band) and $1350 \mathrm{~cm}^{-1}$ ( $D$ band) can be observed in Fig. 1. The $G$ band around $1580 \mathrm{~cm}^{-1}$ is assigned to the $E_{2 g}$ symmetry mode of ideal graphite, which involves the in-plane bond-stretching motion of pairs of $\mathrm{sp}^{2}$-hybridized $\mathrm{C}$ atoms in aromatic and olefinic molecules. The $D$ band around $1350 \mathrm{~cm}^{-1}$ is a breathing mode of $A_{1 g}$ symmetry involving phonons near the $K$ zone boundary and only active in the disorder carbon. ${ }^{29}$

Previous studies have reported on the decomposition of soot by $\mathrm{O}_{3} \cdot{ }^{22,23}$ The signal intensities of soot should, therefore, decrease with reaction time due to the consumption of soot in the reaction. As can be seen in Fig. 1A, however, the signal intensities of $D$ and $G$ bands increased significantly with reaction time within the first $6 \mathrm{~h}$, after which little change was observed. In Fig. 1B, the Raman signal intensity of soot in the control experiment, in which no $\mathrm{O}_{3}$ was introduced into the reactor, also increased slightly with purging time, while no spectral change was observed for the same sample in static air (not shown). It is speculated, therefore, that the increase in signal intensity in Fig. 1 is partially related to the removal of surface organic impurities after being purged with simulated air or oxidized by $\mathrm{O}_{3}$, which decreased the fluorescence interference and led to increased signal intensity of soot. The increase in the rate of Raman signal intensity in Fig. 1A, however, is much larger than that in Fig. 1B. An increase in the aggregate fractal dimension can lead to stronger scattering interaction and stronger electromagnetic coupling between primary spherules of soot. ${ }^{30}$ Thus, if the fractal dimension of soot was enhanced during the ozonization reaction, the Raman signal should increase significantly.

\section{Structural changes of soot during heterogeneous reaction with $\mathrm{O}_{3}$}

For carbonaceous materials, a detailed analysis of the first-order Raman spectra can reveal the presence of several bands by using multi-wavelength excitation ${ }^{30-32}$ and provide fine structural 

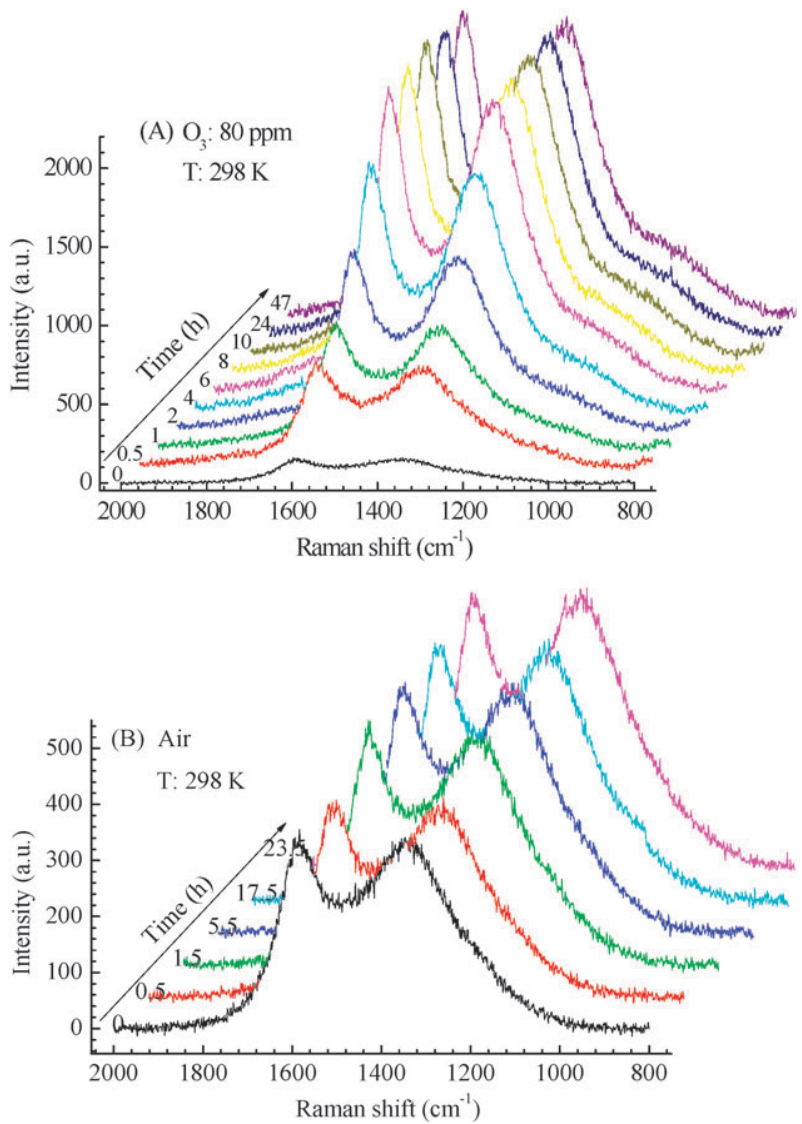

Fig. 1 In situ Raman spectra of soot in the range of $800-2000 \mathrm{~cm}^{-1}$ at $298 \mathrm{~K}(\mathrm{~A})$ in $80 \mathrm{ppm} \mathrm{O}_{3}$, (B) in air.

information of carbonaceous materials by curve fitting procedures. ${ }^{31-33}$ Usually, five bands $(G, D 1, D 2, D 3$, and $D 4)$ are identified by curve fitting in the first-order Raman spectra. ${ }^{31,32}$ The $G$ band, centered at about $1580 \mathrm{~cm}^{-1}$, corresponds to the $E_{2 g}$ symmetry mode of the ideal graphitic lattice as mentioned above. The $D 1$ band around $1350 \mathrm{~cm}^{-1}$ is attributed to the $A_{1 g}$ symmetry mode of the disordered graphitic lattice (graphene layer edges). The $D 2$ band, centered at around $1620 \mathrm{~cm}^{-1}$, originates from the $E_{2 g}$ symmetry stretching mode of disordered graphitic lattice (surface graphene layers). The $D 3$ band around $1500 \mathrm{~cm}^{-1}$ is related to amorphous carbon, which has any mixture of $\mathrm{sp}^{3}, \mathrm{sp}^{2}$ and even sp sites. ${ }^{29}$ The $D 4$ band at $1180 \mathrm{~cm}^{-1}$ is assigned to the $A_{1 g}$ symmetry mode of disordered graphitic lattice. Polyenes and ionic impurities also contribute to the $D 4$ band. ${ }^{31,32}$ Sadezky et $a l .{ }^{31}$ have compared nine different band combinations and demonstrated that the best fit to the Raman spectra for a wide range of soot samples was obtained with four Lorentzian bands $(G, D 1, D 2$, and $D 4)$ and one Gaussian band $(D 3){ }^{31,33}$ Therefore, we also performed curve fitting using PeakFit software with the same procedure.

Fig. 2 shows the curve fitting results for the fresh soot in air and the ozonized soot in $80 \mathrm{ppm} \mathrm{O}_{3}$ for $47 \mathrm{~h}$ at $298 \mathrm{~K}$. As shown in Fig. 2A, the curve fitting result for the fresh soot sample demonstrates strong agreement with the experimental spectrum. Those spectra with short exposure time $(<2 \mathrm{~h})$ to $\mathrm{O}_{3}$ also present good curve fitting results. The correlation coefficients are greater than 0.990 . For spectra with longer exposure time, however, large residuals around $1060 \mathrm{~cm}^{-1}$ and $1750 \mathrm{~cm}^{-1}$ were observed. For example, Fig. 2B shows the curve fitting results of soot aged with $80 \mathrm{ppm}_{3}$ for $47 \mathrm{~h}$ at $298 \mathrm{~K}$. The fitted results (red line) in these two ranges are significantly lower than the experimental value (black line), which suggests that some surface species may contribute to the Raman scattering in these two regions.

Using FTIR, Daly and Horn ${ }^{11}$ observed the formation of ketone species on soot produced by toluene and diesel (bands at $1720 \mathrm{~cm}^{-1}$ for toluene soot, $1725 \mathrm{~cm}^{-1}$ for diesel soot) and lactone $\left(1765 \mathrm{~cm}^{-1}\right)$ and anhydride species (1765 and $1844 \mathrm{~cm}^{-1}$ ) for the heterogeneous reactions of soot with $\mathrm{O}_{3}$. Decesari et $a .^{24}$ also detected the aromatic polyacids by chromatography and HNMR in the water soluble organic compounds extracted from soot oxidized by ozone. The polyacids were ascribed to the hydrolysis of lactone and anhydride species. The regions around $1060 \mathrm{~cm}^{-1}$ and $1750 \mathrm{~cm}^{-1}$ in Fig. 2 can, therefore, be ascribed to the formation of surface ketone, lactone, and anhydride species. To confirm this assumption, the in situ infrared spectra for the heterogeneous reaction of soot with $\mathrm{O}_{3}$ were measured by DRIFTS. The soot sample diluted with $\mathrm{KBr}$ to $1: 200$ was exposed to $80 \mathrm{ppm} \mathrm{O}_{3}$ in simulated air at $298 \mathrm{~K}$ and the unreacted sample was used for reference spectrum collection. The IR spectra in the range of $1450-2000 \mathrm{~cm}^{-1}$ are shown in Fig. 3. A broad band from
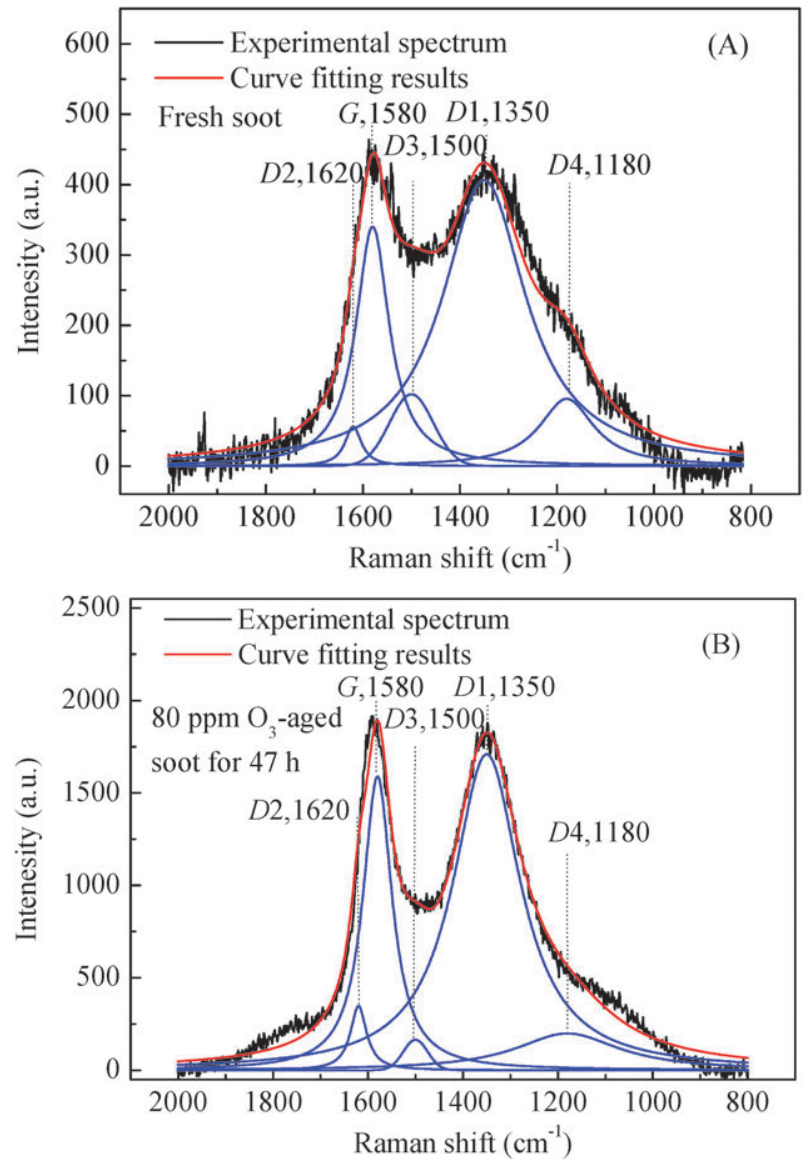

Fig. 2 Curve fitting results based on five bands for (A) fresh soot in air, (B) soot aged with $80 \mathrm{ppm} \mathrm{O}_{3}$ for $47 \mathrm{~h}$ at $298 \mathrm{~K}$. 


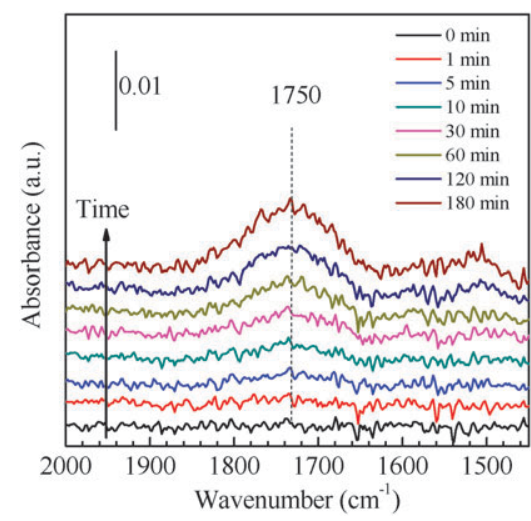

Fig. 3 In situ infrared spectra in the range of $1450-2000 \mathrm{~cm}^{-1}$ of soot in $80 \mathrm{ppm} \mathrm{O}_{3}$ at $298 \mathrm{~K}$.

1620 to $1840 \mathrm{~cm}^{-1}$, which increased with time, was observed (Fig. 3). This band can be assigned to the stretch vibration of the carbonyl group $(\mathrm{C}=\mathrm{O})$ in ketone, lactone and anhydride species. However, the corresponding vibration frequency of $\mathrm{C}-\mathrm{O}$ groups in lactone and anhydride around $1030-1080 \mathrm{~cm}^{-1}$ was not observed due to the weak infrared absorption, while this band is Raman active.

To obtain the structural parameters of soot during the reaction, in addition to the five bands mentioned above, two Gaussian bands at $1060 \mathrm{~cm}^{-1}$ and $1750 \mathrm{~cm}^{-1}$ in the Raman spectra, which originated from the stretch vibration of $\mathrm{C}-\mathrm{O}$ and $\mathrm{C}=\mathrm{O}$ in ketone, lactone, and anhydride species mentioned above, were considered during the curve fitting procedure of the Raman spectra. Fig. 4 shows the curve fitting result of soot aged with $80 \mathrm{ppm} \mathrm{O}_{3}$ at $298 \mathrm{~K}$ for $47 \mathrm{~h}$. A larger correlation coefficient $(0.997)$ is obtained in Fig. 4 when compared with that in Fig. 2B (0.994). Particularly, the fitted curve (red line) coincides well with the experimental curve (black line) in these two regions.

Full widths at half maximum (FWHMs) of $D$ and $G$ bands reflect the degree of order of carbonaceous materials. The broader bands correspond to more disordered materials. ${ }^{32,34}$ Fig. 5A shows the temporal changes in FWHM of the seven bands shown in Fig. 4 from 2 h to $47 \mathrm{~h}$ during reaction with $\mathrm{O}_{3}$. The error bars demonstrate the standard deviations of three times of independent curve fitting results for one spectrum. As shown in Fig. 5A, the FWHMs of the D4, D3, and $D 2$ bands decreased from $180.3 \pm 7.8 \mathrm{~cm}^{-1}$ to $153.4 \pm$ $0.3 \mathrm{~cm}^{-1}$, from $88.2 \pm 3.5 \mathrm{~cm}^{-1}$ to $66.9 \pm 0.2 \mathrm{~cm}^{-1}$, and from $48.2 \pm 1.0 \mathrm{~cm}^{-1}$ to $39.2 \pm 0.02 \mathrm{~cm}^{-1}$, respectively. However, the FWHMs of the bands at $1750 \mathrm{~cm}^{-1}$ and $1060 \mathrm{~cm}^{-1}$ increased from $12.1 \pm 2.7 \mathrm{~cm}^{-1}$ to $102.0 \pm 2.2 \mathrm{~cm}^{-1}$ and from $66.7 \pm 1.6 \mathrm{~cm}^{-1}$ to $110.7 \pm 0.4 \mathrm{~cm}^{-1}$, respectively. Little change for the FWHMs of the $G$ and the $D 1$ bands were observed. These results suggest that heterogeneous reaction of soot with $\mathrm{O}_{3}$ increases the uniformity of disordered graphitic lattice, polyenes, or ionic impurities ( $D 4)$, amorphous carbon (D3), and disordered graphitic lattice at surface graphene layers (D2). This implies that these sites may be consumed in the heterogeneous reaction. However, the degree of order of ketone, lactone, and anhydride (1750 and $\left.1060 \mathrm{~cm}^{-1}\right)$ decreased significantly with reaction time, implying these

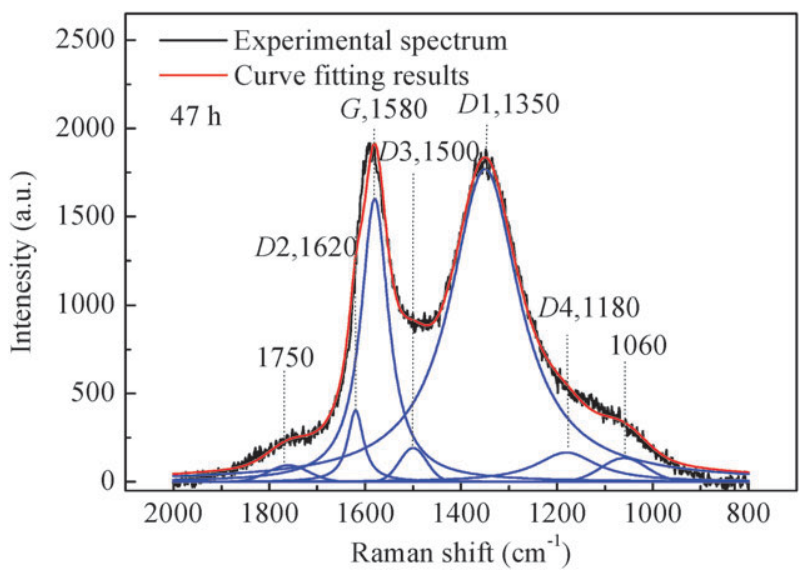

Fig. 4 Curve fitting results based on seven bands of soot aged with $80 \mathrm{ppm} \mathrm{O}_{3}$ for $47 \mathrm{~h}$ at $298 \mathrm{~K}$.

species were formed at different sites during the reaction. The heterogeneous reaction had little effect on the ideal graphitic lattice $(G)$ and graphene layer edges of disordered graphitic lattice $(D 1)$.

Fig. 5B shows the change of integrated area percentages for each band. The integrated areas of bands D3 and D4 decreased from $(3.70 \pm 0.26) \%$ to $(1.93 \pm 0.01) \%$ and from $(6.36 \pm 0.01) \%$ to $(5.08 \pm 0.01) \%$, respectively. The integrated areas of the $1060 \mathrm{~cm}^{-1}$ band and the $1750 \mathrm{~cm}^{-1}$ band gradually increased from $(0.66 \pm 0.06) \%$ to $(2.23 \pm 0.01) \%$ and from $(0.01 \pm 0.005) \%$ to $(1.37 \pm 0.06) \%$, respectively. These results further confirm the consumption of the D3 and $D 4$ bands, and the formation of ketone, lactone, and anhydride species in the reaction. However, although the $D 2$ band's FWHM decreased slightly with reaction time (Fig. 5A), little change in the integrated area percentage was observed. This implies that only a small part of the surface graphene layers contribute to the heterogeneous reaction. These data also indicate that different soot regions have different reactivity with $\mathrm{O}_{3}$. Using HR-TEM and SEM, modification of the graphitic nature and alteration of the surface structure of soot particles were observed after the ozonization reaction, ${ }^{11}$ which revealed regions of different reactivity presenting within a given soot sample, which agrees well with results from this study.

As for the oxidation processes of soot with $\mathrm{O}_{2}$ at high temperature, Iveleva et al. $^{33}$ and Knauer et al. ${ }^{35}$ observed a decrease in FWHMs of both $D 1$ and D3 bands for a spark discharge generated (GfG) soot with reaction time at $523 \mathrm{~K}$ and $573 \mathrm{~K}$ and with reaction temperature (500-900 K). Their results suggest that the degree of order for the graphene layer edges of disordered graphitic lattice and amorphous carbon increased greatly when oxidized by $\mathrm{O}_{2}$ at high temperature. Our results, however, revealed that it was difficult for the $D 1$ band of the sample to react with $\mathrm{O}_{3}$ at room temperature. This difference may be related to the different soot sources and different reaction conditions.

Fig. 6 shows changes in the relative intensity of $D 3(R 3)$ for the soot sample in air and in $80 \mathrm{ppm} \mathrm{O}_{3}$ with time, in which $R 3=I_{D 3} / I_{(G+D 2+D 3)^{3,35}}$ and $I$ is the integrated area for a given band. A significant decrease in $R 3$ from $0.20 \pm 0.01$ to 

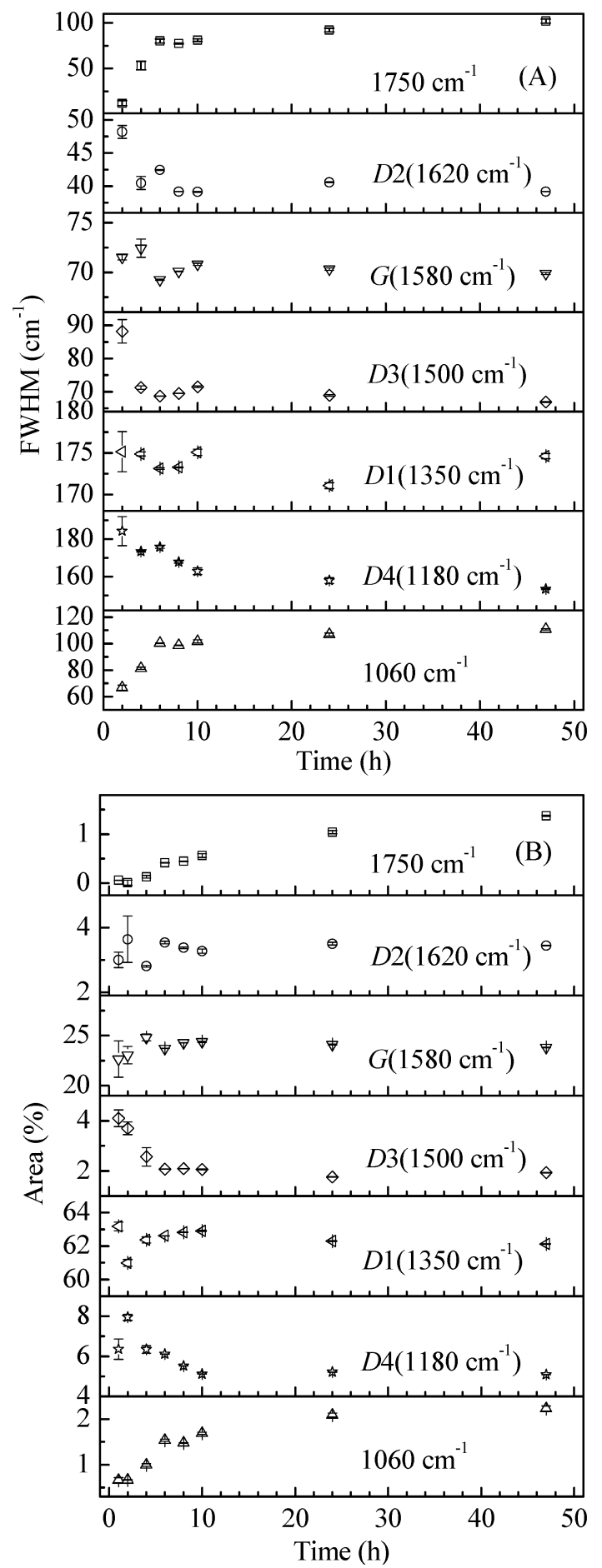

Fig. 5 Temporal changes in (A) FWHM (B) percentage of integrated area for each band in reaction.

$0.07 \pm 0.01$ was observed for the sample exposed to $\mathrm{O}_{3}$, while no significant changes were observed in air. The relative intensity of $D 1(R 1)$, which is similar to $R 3$ and defined as $R 1=I_{D 1} / I_{(G+D 1+D 2)},{ }^{33,35}$ were also calculated and showed no prominent change with time for the soot samples exposed to both air and $\mathrm{O}_{3}$. This means amorphous carbon was able to be oxidized rapidly by $\mathrm{O}_{3}$ with a high reactivity, while the graphene layer edges of the disordered graphitic lattice showed

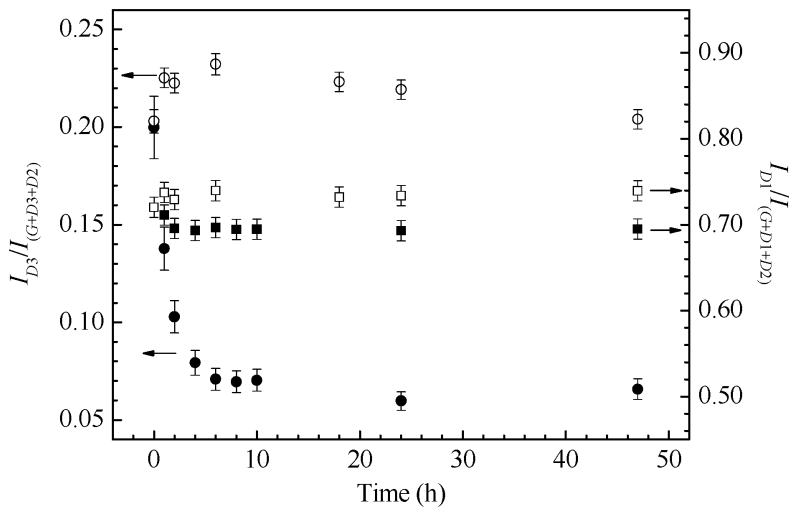

Fig. 6 Changes in $R 1\left(=I_{D 1} / I_{(G+D 1+D 2)}\right)$ and $R 3\left(=I_{D 3} / I_{(G+D 2+D 3)}\right)$ in the heterogeneous reaction. $\bigcirc$ and $\square$ represents the change of $R 3$ and $R 1$ for the soot exposed to air, respectively; and $\boldsymbol{\square}$ represents the changes of $R 3$ and $R 1$ for the soot exposed to $80 \mathrm{ppm} \mathrm{O}_{3}$, respectively.

very limited oxidization by $\mathrm{O}_{3}$. This phenomenon is similar to the heterogeneous oxidation of $\mathrm{GfG}$ soot by $\mathrm{O}_{2}$ at high temperature, ${ }^{33,35}$ in which a decrease in the FWHM of the $D 1$ band was observed with no prominent decrease in $R 1$. This demonstrates that the graphene layer edges of the disordered graphitic lattice have low reactivity with $\mathrm{O}_{2}$ at high temperature.

\section{Morphological changes of soot agglomerates due to heterogeneous reaction with $\mathrm{O}_{3}$}

Fig. 7A shows the typical TEM images of fresh Printex U soot aggregates, illustrating a chain-like agglomerated structure of small spherical primary particles. Fig. 7B shows the typical morphology of soot ozonized with $80 \mathrm{ppm}$ of $\mathrm{O}_{3}$ for $19 \mathrm{~h}$ at $298 \mathrm{~K}$, which also demonstrates an agglomerated structure characteristic. However, the ratio of maximum length $(L)$ to average width of aggregates $(W)$ decreased from $3.1 \pm 1.0$ (for fresh soot) to $2.1 \pm 0.5$ (for ozonized soot).

Fig. 8 shows the diameter distribution of primary soot particles before and after ozonization with $80 \mathrm{ppm}$ of $\mathrm{O}_{3}$. The proportion of spherical particles with large diameter $(>40 \mathrm{~nm})$ of fresh soot was significantly greater than that of ozonized soot, while the opposite was observed for small particles $(<25 \mathrm{~nm})$. The average diameter $\left(\bar{d}_{p}\right)$ of primary particles was $36.9 \pm 9.4 \mathrm{~nm}$ for the fresh soot and $29.9 \pm 7.7 \mathrm{~nm}$ for the ozonized soot. The decrease amplitude in $\bar{d}_{p}$ was about $19 \%$.

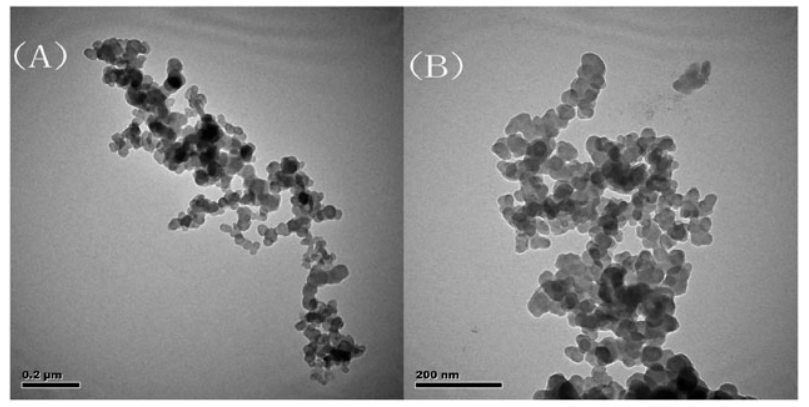

Fig. 7 TEM images of Printex $U$ soot aggregates (A) before and (B) after ozonized with $80 \mathrm{ppm}$ of $\mathrm{O}_{3}$ for $19 \mathrm{~h}$. 


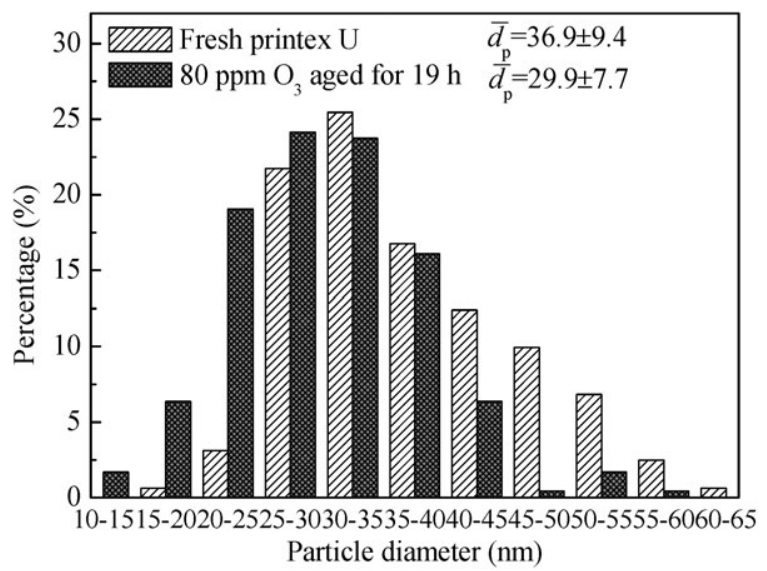

Fig. 8 Diameter distribution of primary soot particles before and after ozonized with $80 \mathrm{ppm}$ of $\mathrm{O}_{3}$ for $19 \mathrm{~h}$.

Additionally, the smaller standard deviation $(\sigma)$ of diameter for the ozonized soot demonstrated an increase in the degree of order after the heterogeneous reaction with $\mathrm{O}_{3}$, which supports the Raman results. Sergides et al. ${ }^{36}$ also observed a large decrease in particle diameter $(40 \%)$ of ozonized hexane soot. However, no changes in diameter of primary particle for the ozonization of toluene soot, kerosene soot, and diesel soot were observed. ${ }^{11}$ These results highlight the large difference in reactivity for different origins of soot.

For fractal-like aggregates, the fractal dimension $\left(D_{f}\right)$ is widely used to describe particle morphology. ${ }^{37}$ It is also an important parameter to assess coagulation dynamics ${ }^{38}$ and optical properties of soot. According to past experimental and computational studies, the following empirical and statistical relationships are established to calculate $D_{f}{ }^{37}$

$$
N \cong\left(d_{a} / \bar{d}_{p}\right)^{2 a} \cong\left(L / \bar{d}_{p}\right)^{D_{f}}
$$

Where $N$ is the number of primary particles in an aggregated sample, $d_{\mathrm{a}}=\left(4 A_{\mathrm{a}} / \pi\right)^{1 / 2}$ is the area-equivalent diameter of the measured aggregated projected area $\left(A_{\mathrm{a}}\right), \alpha=1.09$ is an empirical parameter to account for the particle screening on projected TEM images, $L$ is the measured maximum aggregate length.

The $D_{f}$ for the fresh and ozonized soot samples were $1.61 \pm 0.10$ and $1.81 \pm 0.08$, respectively. The errors represent the $\sigma$ for 5-7 representative aggregates. These values are consistent with the consentaneous fractal dimension value of soot $\left(1.5<D_{f}<1.9\right) .{ }^{38}$ A larger $D_{f}$ means the sample is prone to coagulation and reconstruction. Therefore, this result suggests that the aging process of soot by ozone leads to the formation of more compacted aggregates and growth of the secondary particles. Based on the IR and Raman results as discussed above, we can ascribe this increasing coagulation property to the formation of polar products on the surface.

\section{Hygroscopic changes of soot due to heterogeneous reaction with $\mathrm{O}_{3}$}

Soot aerosols play a significant role in radiative balance and cloud formation by acting as a $\mathrm{CCN}^{4,6}$ and ice nuclei (IN). ${ }^{39}$ However, the CCN and IN abilities of soot greatly depend on its hygroscopicity. While several previous studies have investigated the water uptake behavior of newly formed soot particles, ${ }^{40-44}$ only a few have studied the hygroscopicity of $\mathrm{H}_{2} \mathrm{SO}_{4}$ and $\mathrm{O}_{3}$ aged soot samples. ${ }^{5,18}$ The previous studies revealed that the hygroscopicity of soot particles is determined by the particle size, chemical composition, and origins. As discussed in 3.2, the heterogeneous reaction of soot with $\mathrm{O}_{3}$ can produce oxygen containing surface species including ketone, lactone, and anhydride. It can be postulated, therefore, that ozonization may enhance the hygroscopicity of soot.

The water uptake behavior of fresh soot and soot aged with $80 \mathrm{ppm} \mathrm{O}_{3}$ for $19 \mathrm{~h}$ were investigated using a water sorption analyzer at $278.15 \mathrm{~K}$, shown in Fig. 9 as the corresponding adsorption and desorption curves. The water adsorption curve for ozonized soot is higher than that of fresh soot. Additionally, the water adsorption curves on both the fresh and ozonized samples represent a typical type-II adsorption curve. Thus, the experimental data can be fitted with the two parameters BET equation. ${ }^{45}$ The hysteresis loops for both fresh and $\mathrm{O}_{3}$ aged soot reveal a typical Type $H 4$ loop, which is often associated with narrow slit-like pores and agrees well with the agglomerate structural features of soot. Based on the two parameters BET equation, the $V_{\mathrm{m}}$ (adsorption capacity of water at one monolayer) values of fresh soot and ozonized soot were calculated to be $0.88 \mathrm{mmol} \mathrm{g}^{-1}$ and $1.13 \mathrm{mmol} \mathrm{g}^{-1}$, respectively. The corresponding $c$ constant (a constant of adsorbent-adsorbate interaction) values were 4.06 and 4.33 . These values are very close to the corresponding $V_{\mathrm{m}}$ and $c$ values of palas soot investigated by Popovicheva et al. ${ }^{43}$ The larger $c$ constant for $\mathrm{O}_{3}$ aged soot indicates a stronger interaction between water molecules and soot surface, most likely related to oxygen containing surface species. On the other hand, the larger $V_{\mathrm{m}}$ of $\mathrm{O}_{3}$ aged soot also reveals more adsorptive sites due to the heterogeneous reaction. The above results, therefore, confirm a hygroscopic enhancement of soot due to ozonization. Using a humidity tandem differential mobility analyzer (HTDMA), Weingartner et al. ${ }^{18}$ found that the critical supersaturation $\left(S_{\mathrm{c}}\right)$ of $51.5 \mathrm{~nm}, 73 \mathrm{~nm}$, and $108 \mathrm{~nm}$ diesel soot particles decreased from $2.68 \%, 1.69 \%$, and $1.13 \%$ to $2.48 \%, 1.63 \%$, and $1.00 \%$, respectively, when the samples were ozonized with $400 \mathrm{ppb} \mathrm{O}_{3}$. This also indicates that the hygroscopicity of soot is enhanced by the ozonization process. The hygroscopic enhancement of soot after heterogeneous reaction with $\mathrm{O}_{3}$ can, therefore, be ascribed to the formation of oxygen containing surface species and the decrease in primary particle size.

\section{Conclusions}

Using in situ Raman spectroscopy, the FWHMs of $D 3$ and $D 4$ bands of soot during heterogeneous reaction with $\mathrm{O}_{3}$ was observed to decrease from $88.2 \pm 3.5 \mathrm{~cm}^{-1}$ to $66.9 \pm 0.2 \mathrm{~cm}^{-1}$ and from $180.3 \pm 7.8 \mathrm{~cm}^{-1}$ to $153.4 \pm 0.3 \mathrm{~cm}^{-1}$. This indicates that the degree of order of amorphous carbon ( $D 3$ band) and disordered graphitic lattice ( $D 4$ band) of soot increased significantly during the heterogeneous reaction with $\mathrm{O}_{3}$. Their relative integrated intensities (percentages of integrated areas) also decreased from $(3.70 \pm 0.26) \%$ to $(1.93 \pm 0.01) \%$ and from $(6.36 \pm 0.01) \%$ to $(5.08 \pm 0.01) \%$, respectively. This suggests the consumption of amorphous carbon and 


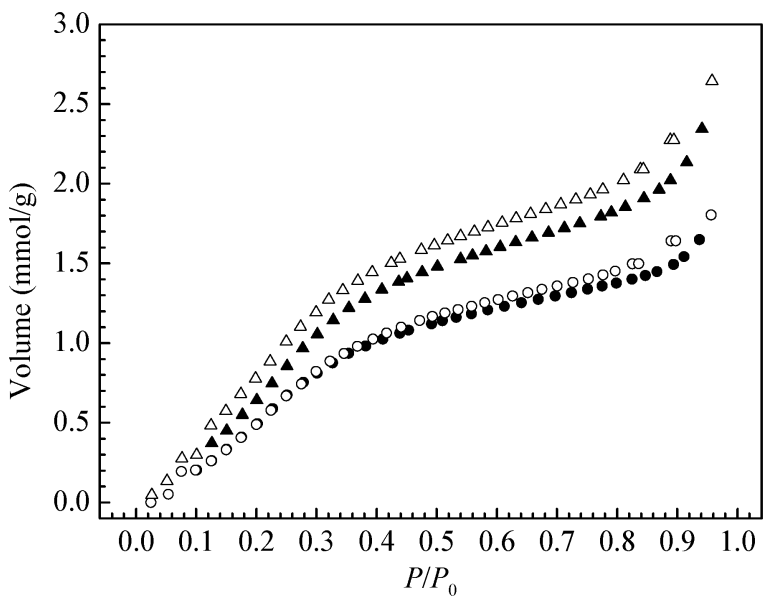

Fig. 9 Water uptake behavior of fresh soot and $\mathrm{O}_{3}$ aged soot at $278.15 \mathrm{~K}$. $\bigcirc$ and $\bigcirc$ represent adsorption and desorption of water by fresh Printex U, respectively; $\boldsymbol{\Delta}$ and $\Delta$ represent adsorption and desorption of water by $80 \mathrm{ppm} \mathrm{O}_{3}$ aged Printex $\mathrm{U}$ for $19 \mathrm{~h}$, respectively.

disordered graphitic lattice during the heterogeneous reaction with $\mathrm{O}_{3}$. We can conclude, therefore, that amorphous carbon and disordered graphitic lattice are the reactive sites for the heterogeneous reaction of soot with $\mathrm{O}_{3}$.

The bands around $1060 \mathrm{~cm}^{-1}$ and $1750 \mathrm{~cm}^{-1}$ in the in situ Raman spectra were ascribed to the formation of oxygen containing surface species including ketone, lactone, and anhydride. After being aged with $\mathrm{O}_{3}$, the average diameter of the primary particles decreased from $36.9 \pm 9.4 \mathrm{~nm}$ to $29.9 \pm 7.7 \mathrm{~nm}$, with an increase in fractal dimension from $1.61 \pm 0.10$ to $1.81 \pm 0.08$. At the same time, the hygroscopicity of soot was enhanced significantly due to ozonization. Based on the two parameters BET equation, the $V_{\mathrm{m}}$ of water increased from $0.88 \mathrm{mmol} \mathrm{g}^{-1}$ for fresh soot to $1.13 \mathrm{mmol} \mathrm{g}^{-1}$ for $\mathrm{O}_{3}$ aged soot. The corresponding $c$ constant also increased from 4.06 to 4.33 . The larger $V_{\mathrm{m}}$ indicates more adsorptive sites for the $\mathrm{O}_{3}$ aged soot, and the larger $c$ constant signifies an increase in interaction between water molecules and soot surface. This enhancement was ascribed to the formation of oxygen containing surface species.

\section{Acknowledgements}

This research was financially supported by the National Natural Science Foundation of China (20907069, 20937004, and 50921064) and the Ministry of Science and Technology, China (2007CB407301).

\section{Notes and references}

1 A. M. Nienow and J. T. Roberts, Annu. Rev. Phys. Chem., 2006, 57, 105-128.

2 A. S. Ackerman, O. B. Toon, D. E. Stevens, A. J. Heymsfield, V. Ramanathan and E. J. Welton, Science, 2000, 288, 1042-1047. 3 M. Z. Jacobson, Nature, 2001, 409, 695-697.

4 W. L. Chameides and M. Bergin, Science, 2002, 297, 2214-2215.

5 R. Y. Zhang, A. F. Khalizov, J. Pagels, D. Zhang, H. X. Xue and P. H. McMurry, Proc. Natl. Acad. Sci. U. S. A., 2008, 105, 10291-10296.
6 S. Menon, J. Hansen, L. Nazarenko and Y. F. Luo, Science, 2002, 297, 2250-2253.

7 IPCC "IPCC Fourth Assessment Report: Working Group I Report The Physical Science Basis", 2007.

8 J. Pagels, A. F. Khalizov, P. H. McMurry and R. Y. Zhang, Aerosol Sci. Technol., 2009, 43, 629-640.

9 Z. F. Lu, J. M. Hao, L. H. Hu and H. Takekawa, J. Aerosol Sci., 2008, 39, 897-903.

10 A. R. Chughtai, J. M. Kim and D. M. Smith, J. Atmos. Chem., 2003, 45, 231-243.

11 H. M. Daly and A. B. Horn, Phys. Chem. Chem. Phys., 2009, 11, 1069-1076.

12 J. McCabe and J. P. D. Abbatt, J. Phys. Chem. C, 2009, 113, $2120-2127$.

13 S. Lelièvre, Y. Bedjanian, N. Pouvesle, J. L. Delfau, C. Vovelle and G. L. Bras, Phys. Chem. Chem. Phys., 2004, 6, 1181-1191.

14 C. F. Wei, S. M. Larson, K. O. Patten and D. J. Wuebbles, Atmos. Environ., 2001, 35, 6167-6180.

15 S. Kamm, O. MöKhler, K. H. Naumann, H. Saathoff and U. Schurath, Atmos. Environ., 1999, 33, 4651-4661.

16 U. Pölschl, T. Letzel, C. Schauer and R. Niessner, J. Phys. Chem. $A, 2001,105,4029-4041$.

17 R. S. Disselkamp, M. A. Carpenter, J. P. Cowin, C. M. Berkowitz, E. G. Chapman, R. A. Zaveri and N. S. Laulainen, J. Geophys. Res., 2000, 105, 9767-9771.

18 E. Weingartner, H. Burtscher and U. Baltensperger, Atmos. Environ., 1997, 31, 2311-2327.

19 Y. A. Aklilu and D. V. Michelangell, Environ. Sci. Technol., 2004, 38, 5540-5547.

20 S. Bekki, J. Geophys. Res., 1997, 102, 10751-10758.

21 A. Alebić-Juretić, T. Cvitaš and L. Klasinc, Chemosphere, 2000, 41, 667-670.

22 D. M. Smith and A. R. Chughtai, J. Geophys. Res., 1996, 101, 19607-19620.

23 D. M. Smith and A. R. Chughtai, J. Atmos. Chem., 1997, 26 , 77-91.

24 S. Decesari, M. C. Facchini, E. Matta, M. Mircea, S. Fuzzi, A. R. Chughtai and D. M. Smith, Atmos. Environ., 2002, 36, $1827-1832$.

25 J. P. A. Neeft, M. Makkee and J. A. Moulijn, Fuel, 1998, 77, $111-119$.

26 K. Villani, W. Vermandel, K. Smets, D. D. Liang, G. V. Tendeloo and J. A. Martens, Environ. Sci. Technol., 2006, 40, 2727-2733.

27 Y. C. Liu, H. He, W. Q. Xu and Y. B. Yu, J. Phys. Chem. A, 2007, 111, 4333-4339.

28 Q. X. Ma, Y. C. Liu and H. He, J. Phys. Chem. A, 2010, 114, $4232-4237$.

29 A. C. Ferrari and J. Robertson, Phys. Rev. B: Condens. Matter Mater. Phys., 2000, 61, 14095-14107.

30 H. X. Xue, A. F. Khalizov, L. Wang, J. Zheng and R. Y. Zhang, Phys. Chem. Chem. Phys., 2009, 11, 7869-7875.

31 S.-K. Sze, N. Siddique, J. J. Sloan and R. Escribano, Atmos. Environ., 2001, 35, 561-568.

32 A. Sadezky, H. Muckenhuber, H. Grothe, R. Niessner and U. Pöschl, Carbon, 2005, 43, 1731-1742.

33 R. Brunetto, T. Pino, E. Dartois, A.-T. Cao, L. d'Hendecourt, G. Strazzulla and Ph. Bréchignac, Icarus, 2009, 200, 323-337.

34 N. P. Ivleva, A. Messerer, X. Yang, R. Niessner and U. Pöschl, Environ. Sci. Technol., 2007, 41, 3702-3707.

35 C. Casiraghi, A. C. Ferrari and J. Robertson, Phys. Rev. B: Condens. Matter Mater. Phys., 2005, 72, 085401.

36 M. Knauer, M. Carrara, D. Rothe, R. Niessner and N. P. Ivleva, Aerosol Sci. Technol., 2009, 43, 1-8.

37 C. A. Sergides, J. A. Jassim, A. R. Chughtai and D. M. Smith, Appl. Spectrosc., 1987, 41, 482-492.

38 M. F. Chandler, Y. W. Teng and U. O. Koylu, Proc. Combust. Inst., 2007, 31, 2971-2979.

39 M. M. Maricq, J. Aerosol Sci., 2007, 38, 141-156.

40 B. Gorbunov, A. Baklanov, N. Kakutkina, H. L. Windsor and R. Toumi, J. Aerosol Sci., 2001, 32, 199-215.

41 S. Seisel, Y. Lian, T. Keil, M. E. Trukhin and R. Zellner, Phys. Chem. Chem. Phys., 2004, 6, 1926-1932.

42 O. Popovicheva, N. M. Persiantseva, N. K. Shonija, P. DeMott, K. Koehler, M. Petters, S. Kreidenweis, V. Tishkova, 
B. Demirdjian and J. Suzanne, Phys. Chem. Chem. Phys., 2008, 10, 2332-2344.

43 O. B. Popovicheva, N. M. Persiantseva, V. Tishkova, N. K. Shonija and N. A. Zubareva, Environ. Res. Lett., 2008, 3, 025009 .
44 O. B. Popovicheva, E. D. Kireeva, N. K. Shonija and T. D. Khokhlova, J. Phys. Chem. A, 2009, 113, 10503-10511.

45 K. S. W. Sing, D. H. Everett, R. A. W. Haul, L. Moscou, R. A. Pierotti, J. Rouqérol and T. Siemieniewska, Pure Appl. Chem., 1985, 57, 603-619. 